\title{
Customer Satisfaction and Price Tolerance
}

\author{
EUGENE W. ANDERSON \\ National Quality Research Center, School of Business Administration, The University of Michigan. Ant Arbor; \\ Michigan $48109-1234$
}

[Received 8-10-95/Accepted 3-21-96)

Key words: customer satisfaction, price sensitivity, industrial organization

\begin{abstract}
This study investigates the association between customer satisfaction and willingness-to-pay or price tolerance. The goal is not only to determine whether the association between customer satisfaction and price tolerance is positive or negative but also to gauge the degree of association. The Swedish Customer Satisfaction Barometer provides the data. The empirical analysis indicates a negative association between the level of customer satisfaction provided by the firm and the degree of price tolerance exhibited by its customers. However, a positive association is found between year-to-year changes in the levels of customer satisfaction and price tolerance.
\end{abstract}

To what extent does improving customer satisfaction increase customer willingness-to-pay or price tolerance and, consequently, decrease price sensitivity? The goal of this study is to investigate whether the association between satisfaction and price tolerance is positive or negative, as well as to gauge the degree of association between these two important constructs. Adding to our understanding of the different ways increasing customer satisfaction can benefit the firm is important to managers considering initiating or continuing such efforts, as well as to researchers interested in developing theory in the area. This is particularly true in the case of price tolerance, as it has not received the degree of attention paid other consequences of satisfaction, such as repurchase intentions (Anderson and Fornell, 1993).

\section{Customer satisfaction and price tolerance}

Customer satisfaction is a post hoc evaluation of consumption experience (Oliver, 1980). A customer satisfaction evaluation can be quite specific in nature-a specific subset of experience such as a single transaction and/or particular attribute-but may also be cumulative, based on all previous experience with a good or service (Anderson and Fornell, 1993). As the purpose of this study is to investigate buyers' price tolerance - the maximum price increased satisfied customers are willing to pay or tolerate before switching - it seems natural to focus on cumulative customer satisfaction. Cumulative customer satisfaction, as opposed to satisfaction with a specific transaction or product attribute, should provide a more accurate depiction of the net or marginal value customers attach to future consumption of a good or service. 
Price tolerance is closely related to the concept of consumer surplus: "the excess of the price which a man would be willing to pay rather than go without having a thing over what he actually does pay is the economic measure of his satisfaction surplus" (Marshall, 1890). Consequently, we might expect customers to have greater price tolerance for products providing greater satisfaction. This would seem to be a fundamental tenet of rational economic behavior.

To illustrate, consider the classical depiction of the relationship between price and demand presented in Figures $1 \mathrm{a}$ and $1 \mathrm{~b}$. As the level customer satisfaction provided by the firm increases, price tolerance should increase. As the price tolerance of each individual increases, the demand curve depicted in Figure la should move upward and outward as shown in Figure 1b.

However, while the hypothesis that an increase customer satisfaction should lead to an increase in price tolerance seems intuitive at first glance, firms providing higher customer satisfaction will not necessarily have customers with greater price tolerance. To see this, consider that although customer satisfaction is found to be higher for firms in more competitive categories (Anderson, 1994), price tolerance may actually be lower as the quality of the "next best" alternative is likely to be more attractive than would be the case in less competitive categories.

\section{Methodological approach}

To investigate the direction and degree of association between customer satisfaction and price tolerance, we posit the following expression for the relationship:

$$
P T_{i t}-\alpha+\beta\left(C S_{i t}\right)+\eta_{i}+\varepsilon_{i t}
$$

where

$P T_{i t}=$ Price tolerance of firm $i$ 's customers at time $t$,

$C S_{i t}=$ Customer Satisfaction for firm $i$ 's customers at time $t$,
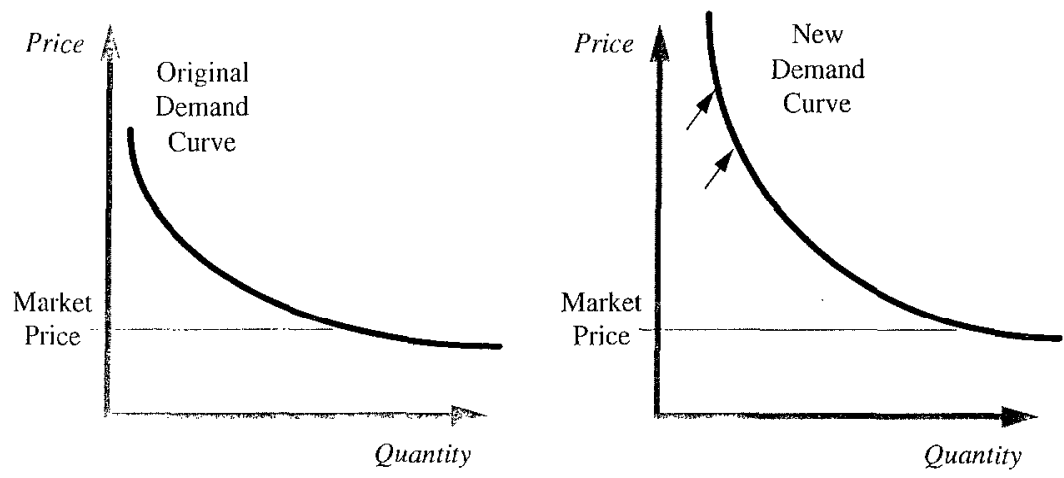

Figure la. Consumer demand prior to an increase in customer satisfaction.

Figure 1 b. Consumer demand following an increase in customer satisfaction. 
$\alpha=$ constant,

$\beta=$ slope coefficient,

$\eta_{i}=$ unobserved fixed factors (e.g., firm or industry characteristics),

$\varepsilon_{i t}=\rho \varepsilon_{i t-1}+u_{i t}=$ autoregressive and random unobserved factors.

The basic linear form of equation (1) is consistent with Bass's (1993) recommendation of describing simply an expected pattern or relationship. However, it must also be recognized that there are a host of factors in addition to customer satisfaction that may be associated with price tolerance (e.g., firm and industry characteristics). Equation (1) explicitly acknowledges the possible existence of these factors as unobserved fixed, autoregressive, and random effects.

Failure to control for unobservable factors can lead to violations of the assumptions of OLS when estimating specifications such as (1) using cross-sectional-time series data. In particular, measurement error and random environmental shocks may create correlation between the residual and the independent variables. Omitted factors correlated with both the dependent and independent variables may also lead to biased estimates. Generally, the degree of bias will depend on the type of problem being studied. For example, even if the correlation between the residual and a regressor is large, the resulting bias will be small if the error variance is small relative to the systematic variance in the model (i.e., $\operatorname{plim} \hat{\beta}=\beta+\rho_{u * x}\left(\sigma_{u} / \sigma_{x}\right)$. However, this is not the case for many marketing phenomena.

To control for potential bias due to each type of omitted effect, equation (1) must be transformed. First, if there are unobservable firm-specific, fixed effects, $/ Z_{i}$, first-differencing $y_{r}-y_{1-1}$, can be employed as a means of controlling for such omitted variables (Maddala, 1977):

$$
P T_{i t}-P T_{i t-1}=\beta\left(C S_{i t}-C S_{i t-1}\right)+\varepsilon_{i t}-\varepsilon_{i t-1}
$$

Second, omitted factors can also give rise to serial correlation between the residuals. Factors that might give rise to serial correlation include accounting practices, management skills, pioneering advantage, and luck. To control for potential bias from autoregressive factors, equation (2) can be $\rho$-differenced, $\rho v_{-1}$, yielding

$$
\begin{gathered}
P T_{i t}-P T_{i t-1}=\rho\left(P T_{i t-1}-P T_{i t-2}\right)+\beta\left(\left(C S_{i t}-C S_{i t-1}\right)-\rho\left(C S_{i t-1}-C S_{i t-2}\right)\right) \\
+u_{i t}-u_{i t-1}
\end{gathered}
$$

Finally, a common approach to controlling for potential sources of measurement error and random effects (e.g., contemporaneous shocks) is the use of instrumental variables. Instrumental variables have the advantage of reducing bias, but the disadvantage of increasing the variance of an estimate. An ideal instrumental variable is one that is uncorrelated with the residual, yet highly correlated with the independent variable. The central issue in choosing an instrumental variable is to determine where to find such a variable. A common solution to this problem is to choose past values of the independent variables lagged at least one period beyond the error term. As instrumenting removes 
firm-specific random effects but not those affecting the entire sample, we control for unobservable period-specific factors (such as economywide factors) by including annual dummy variables.

\section{Description of the data}

The Swedish Customer Satisfaction Barometer (SCSB) provides data on both customer satisfaction and price tolerance useful for estimating each of the preceding specifications. The SCSB provides coverage of a major portion of the Swedish economy (Fornell, 1992). ${ }^{1}$ As such it includes not only packaged, nondurable goods (a relatively small portion of the economy) but also a wide variety of manufactured durable goods and retailers, as well as many different types of services. The firms included in the database study represent major competitors in a wide variety of industries: Airlines, automobiles, banking (consumer and business), charter travel, clothing retail, department stores, furniture stores, gas stations, insurance (life, auto, and business), mainframe computers (business), PCs (business), newspapers, shipping (business), and supermarkets. The companies surveyed in each industry are the largest share firms such that cumulative share is approximately 70 percent.

The data on each firm are collected via a computer-assisted telephone survey that is national in scope. Respondents are screened on the basis of whether they are customers of firms included in the SCSB. The ensuing interview-which includes questions that range from the antecedents of satisfaction (such as expectations, perceived quality) to the consequences of satisfaction (word-of-mouth, complaining behavior) -average eight minutes in length.

The survey instrument and approach have been continually tested and refined. Extensive pretesting of questions for each product category is conducted. Once collected, the data provide the basis for measuring key constructs of interest, including an index representing each firm's level of customer satisfaction, $C S_{i t}$ ' The indices are generated using a latent variable methodology described by Fornell (1992). Each index represents a weighted average based on the weights obtained from the latent variable estimation. As discussed by Fornell (1992), the observed reliability and validity of the obtained indices is high. These satisfaction indices have proven to be well predicted by appropriate antecedents and perform favorably as predictors of presumable consequences such as loyalty and profitability (Anderson, Fornell, and Lehmann, 1994; Fornell, 1992; Johnson, Anderson, and Fornell, 1995; Johnson and Fornell, 1993).

As a basis for measuring price tolerance, respondents are asked for the relative price increase they would be willing to tolerate before switching: "If other brands remain at the same prices, how much can raise its price before you would not choose another the next time you buy?" Respondents provide an answer in percentage terms. Providing a response in percentage-rather than absolute-terms helps address concerns about comparing price tolerance across industries. This approach is also consistent with Pessemier's (1959) suggested measure of brand loyalty as the minimum increase customers are willing to tolerate before switching. Although it has been 
argued that identifying price tolerance for untried products may be difficult (Morrison, 1979), the focus of SCSB is on customer's perceptions of the price increase they will tolerate for currently used products. As Olson and Jacoby (1971) find that this measure takes into account both attitudinal and behavioral components of brand loyalty - and has high reliability as a repeated measured - the construct validity of this measure should be high.

The price tolerance variable has not been extensively examined in previous studies using SCSB data, apart from summary information on the customer satisfaction-price tolerance relationship provided by Fornell (1992). In estimating a linear relationship between customer satisfaction and loyalty at the individual level-price tolerance is one of several multiple indicators of the latter construct-for each firm, Fornell (1992) reports an overall positive relationship, as might be expected. This study extends the investigation to the effect of the overall level of customer satisfaction provided by the firm on the overall level of price tolerance enjoyed by the firm's customers. For the analysis, the price tolerance variable is averaged over the respondents for each firm to obtain an average for each firms ' buyers, $P T_{i t}$.

In terms of sample size, the SCSB collects approximately 200 individual-level observations per firm per year (this number can be lower for business-to-business categories). There are 62 firms from 1989, 81 firms from 1990, 87 firms from 1991 and 1992, 92 firms from 1993, and 94 firms from 1994, for a total of 503 firm-level observations. The total number of individual observations for the 503 firms in the analysis is 102,271 . The sample for the current study includes all firms for which the SCSB collected customer satisfaction and price tolerance data for at least four consecutive years during the period spanning the years 1989 through 1994. The four-year requirement is imposed due to the methodological transformations described below. The final number of observations available for analysis is 475 .

\section{Findings}

The empirical findings concerning the association between customer satisfaction and price tolerance differ depending on the degree to which the empirical analysis controls for unobservable factors. Table 1 summarizes the results of estimating the relationship as specified by (1) equation (1) - the simple linear specification wherein no effort is made to control for unobservable factors, (2) equation (2)-controls for fixed unobservable factors via first-differencing, and (3) equation (3)-controls for fixed and autoregressive unobservable factors via first-differencing in conjunction with $\rho$-differencing. To illustrate the effect of controlling for random unobservable factors, each equations is estimated both with and without the use of instrumental variables lagged one period beyond the error term $(t-1$ for equation (1) and $t-2$ for equations (2) and (3)).

The estimation results for equation (1) do not support the intuitive hypothesis of a positive association between customer satisfaction and price tolerance. Whether or not instrumental variables are used to control for unobserved random effects, the estimated coefficient is negative and significant. While this finding is likely due to lack of control for 
Table 1. Summary of the empirical association between price tolerance, $P T$, and satisfaction, $C S$.

\begin{tabular}{lcccccc}
\hline & \multicolumn{3}{c}{ Without Instrumental Variables } & \multicolumn{3}{c}{ With Instrumental Variables } \\
\cline { 2 - 3 } & Eq. (1) & Eq. (2) & Eq. (3) & Eq. (1) & Eq. (2) & Eq. (3) \\
\hline Constant, $\alpha$ & $13.12^{*}$ & & & $16.11^{*}$ & & \\
$C S$ & $-0.07^{*}$ & $0.12^{*}$ & $0.04^{* *}$ & $-0.12^{*}$ & $0.08^{*}$ & $0.06^{* *}$ \\
1990 & 0.05 & -0.13 & & & & \\
1991 & 0.33 & -0.22 & -0.09 & 0.41 & & \\
1992 & 0.28 & 0.03 & 0.09 & 0.52 & $-0.49^{*}$ & \\
1993 & 0.51 & $0.48^{*}$ & $0.37^{*}$ & $0.80^{* *}$ & -0.14 & $0.26^{* *}$ \\
1994 & $1.58^{*}$ & $1.02^{*}$ & $1.18^{*}$ & $1.79^{*}$ & $1.07^{*}$ & $1.05^{*}$ \\
$S S E$ & 4264.27 & 1391.62 & 526.13 & 3359.44 & 510.60 & 162.30 \\
$F_{y, y}$ & $4.47^{*}$ & $6.01^{*}$ & $12.88^{*}$ & $7.243^{*}$ & $11.62^{*}$ & $21.55^{*}$ \\
$\rho$ & \multicolumn{7}{c}{} & -0.07 & & & 0.05 \\
$n$ & 475 & 388 & 302 & 394 & 217 & 131 \\
\hline
\end{tabular}

Note: Eq. (1): $P T_{i t}=\alpha+\beta\left(C S_{i t}\right)+\eta_{i}+\mathcal{E}_{i t}$.

Eq. (2): $P T_{i t}-P T_{i t-1}=\beta\left(C S_{i t}-C S_{i t-1}\right)+\varepsilon_{i t}-\varepsilon_{i t-1}$.

Eq. (3): $P T_{i t}-P T_{i t-1}=\rho\left(P T_{i t}-1-P T_{i t-2}\right)+\beta\left(\left(C S_{i t}-C S_{i t-1}\right)-\rho\left(C S_{i t-1}-\right.\right.$ $\left.\left.C S_{i t-2}\right)\right)+u_{i t}-u_{i t-1}$.

*Indicates $p<0.01$.

** Indicates $p<0.10$.

unobservable effects (Hausman's specification test to determine whether omitted variables are a problem is significant at $H=5.53^{*}$ ), it nevertheless serves to highlight the distinct nature of customer satisfaction and price tolerance as to two related - but clearly not identical-constructs. If the two constructs were identical or nearly so, then one would expect the observed association between the two to be unaffected by efforts to control for omitted factors. Hence, the association between customer satisfaction and price tolerance is more interesting than might be suspected without looking beyond the obvious or expected positive relationship between the two.

When steps are taken to control for unobserved fixed and autoregressive effects, however, the findings do suggest support for the intuitive hypothesis. As shown in Table 1, the estimated coefficient for satisfaction is positive and significant for equations (2) and (3) whether or not instrumental variables are included. Using Hausman's specification test to select the best model reveals that equation (3) does not provide a significant improvement over equation (2) in either case, indicating that autoregressive effects should not be a concern $(H=0.34$ and $H=1.01)$. The relatively small estimate for the autoregressive parameter is also insignificant in both cases. However, Hausman's test does favor the use of instrumental variables in equation $(2)\left(H=3.31^{* *}\right)$. Hence, the appropriate estimate of the association between satisfaction and price tolerance, based on the instrumental variable version of Equation (2), is 0.08 .

Given the sample's mean levels of customer satisfaction (65.57) and price tolerance (8.75), the estimated coefficient of 0.08 implies an elasticity of 0.60 . This suggests that in increasing customer satisfaction by 1 percent, firms increase the marginal value of their product relative to alternatives by six-tenths of 1 percent $(0.60)$. This association between a change in customer satisfaction and a change in price tolerance suggests, in turn, that 
increases in customer satisfaction should also be associated with reduced price elasticity of demand.

Hence, once the influence of unobservables is accounted for, the expected positive association between customer satisfaction and price tolerance emerges. In part, this may be due to the differential effects that industry characteristics have on the two constructs. Regardless of the source, when steps are taken to enable the empirical analysis to focus on within firm changes in customer satisfaction and price tolerance, the intuitive result holds.

Finally, a peripheral - but potentially interesting-aspect of the empirical analysis is the pattern exhibited by the coefficients for the annual dummy variables. ${ }^{2}$ The rising levels of the coefficient in each subsequent year likely reflects the improving Swedish economy as it emerges from the recessionary period of the late $1980 \mathrm{~s}$ and early $1990 \mathrm{~s}$. At the same time that the economy is improving, price tolerance appears to be increasing.

\section{A peek at an unobservable: competitiveness}

If equation (1) is biased by lack of control for unobservable fixed effects, then what factors might account for the difference in sign from the coefficients found in estimating equations (2) and (3)? One possibility is that there is systematic variation in the levels of customer satisfaction and price tolerance due to industrial organization characteristics such as competitiveness. As competition in an industry increases, firms provide greater customer satisfaction as they compete to attract and retain customers (Anderson, 1994; Fornell, 1992). However, increasing competition may actually lower price tolerance. Put simply, as the availability of attractive alternatives increases, the maximum price increase buyers will tolerate before switching should fall. At the same time, lower price tolerance may, in turn, encourage firms to increase customer satisfaction in order to retain their customers. Conversely, customer satisfaction may be lower when there is less competition, yet price tolerance may be high due to lack of altematives and/or switching costs.

To further explore the possibility that competition is one of the underlying factors leading to a spurious negative association between levels of customer satisfaction and price tolerance, it seems reasonable to include a measure of competition in equation (1), Competitiveness, as measured by degree of concentration, may affect the level of satisfaction in an industry, as well as the importance of the various antecedents. Low concentration (greater competition) should be associated with greater effort to satisfy customers and, hence, greater customer satisfaction. A proxy for the degree of concentration, $C O N C$, is generated by taking the inverse of the number of competitors comprising 70 percent of the sales in each respective industry. Anderson (1994) employs this measure in finding that higher concentration levels are associated with lower quality and, therefore, lower customer satisfaction.

Including the concentration measure as an independent variable in equation (1)-with instrumental variables - yields (standard errors are given in parentheses and an asterisk indicates $p$-value less than 0.10 ): 


$$
\begin{aligned}
& P T_{i t}=-12.71-0.08^{*} C S_{i t}+2.95 * C O N C+0.49 D 91+0.57 D 92+0.87 * D 93+1.89 * D 94
\end{aligned}
$$

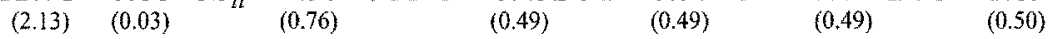

$$
\begin{aligned}
& \mathrm{SSE}=3232.38 \quad F_{\nu, \nu}=8.80 \quad n=394
\end{aligned}
$$

Hence, there is a significant and positive association between the level of concentration in a category and the level of price tolerance. This implies that, in terms of competition, lower price tolerance is associated with greater competition. However, the findings do indicate the association between the level of customer satisfaction and the level of price tolerance remains negative, indicating other factors-and possibly better measures of competitiveness - may be needed to explain the observed association between the two.

\section{Discussion}

This article examines the relationship between customer satisfaction and price tolerancethe maximum price increase satisfied customers are willing to pay or tolerate before switching. The study finds a positive association between changes in customer satisfaction and changes in price tolerance but a negative association between the level of customer satisfaction and the level of price tolerance.

From the perspective of the firm, the findings imply that increasing customer satisfaction is likely to decrease price elasticity of demand. In particular, the findings imply a 1 percent increase in customer satisfaction should be associated with a 0.60 percent decrease in price sensitivity. Firms considering whether to pursue improvements in customer satisfaction-and in an increasing number of situations whether to curtail such efforts-should consider the financial benefits of improving satisfaction as a consequence of customers' increased willingness to tolerate price increases. As price tolerance also provides an important indicator of loyalty, firms interested in assessing the longterm benefits of customer satisfaction should consider using price tolerance measures along with more traditional measures of loyalty, such as repurchase intentions and willingness to recommend.

The findings also indicate that greater competitiveness in an industry is associated with lower price tolerance and therefore greater price sensitivity. At the same time, greater competitiveness is associated with higher levels of customer satisfaction. As the two constructs differ in how each varies with the level of competitiveness, this suggests not only that the two constructs are different but that the relationship between the two is not a simple, positive, and monotonic one. Rather, this finding seems quite reasonable in that it indicates both price and quality are of heightened importance in more competitive industries. Within a particular industry, however, one might expect price sensitivity to decrease as customer satisfaction increases, as suggested by the findings when steps are taken to control for unobservable differences in industry characteristics.

There are several potential avenues for future research addressing issues beyond the scope of the current article. First, there is room for empirical work aimed at developing a 
better understanding for how both customer satisfaction and price tolerance vary across categories due to industrial organization factors such as the degree of competition. The empirical analysis for the case in which there are no explicit controls for unobservable factors suggests not only that customer satisfaction and price tolerance are distinct constructs worthy of such studies in their own right but that there is substantial unexplained variation that may be systematic in nature.

A second important direction for future research would be to replicate the current study both in the field and in the laboratory. For the latter, the tools of experimental economics provide an opportunity to replicate the findings in a controlled setting. Concerning the former, in a few years the U.S. version of the Swedish index-currently in its second year of data collection - will provide a test of whether the Swedish findings generalize. This might be expected to be the case, given that previous studies suggest that empirical relationships observed based on satisfaction studies of Swedish consumers replicate quite well in the United States (Anderson, 1995; Wikstrom, 1983).

\section{Acknowledgments}

The author gratefully acknowledges the data provided through the funding of the Swedish Post and the support of both the National Quality Research Center at the University of Michigan Business School and the International Center for Studies of Quality and Productivity at the Stockholm School of Economics. The author would also like to thank Claes Fornell and Michael D. Johnson for their valuable comments, as well as Jaesung Cha. for his work in assembling the data set.

\section{Notes}

1. The SCSB is an ongoing project managed by the National Quality Research Center (NQRC) at the University of Michigan Business School and the International Center for Studies of Quality and Productivity (ICQP) at the Stockholm School of Economics, Fornell (1992) describes the SCSB in detail.

2. Reassuringly, too, the substantive implications of the analysis do not change if the annual dummies are excluded.

\section{References}

Anderson, Eugene W. (1994). "Cross-Category Variation in Customer Satisfaction and Retention." Marketing Letters 5(1) (January), 19-30.

$\Lambda$ nderson, Eugene W. (1995). "Word of-Mouth as a Consequence of Customer Satisfaction." Working Paper, National Quality Research Center, Michigan Business School.

Anderson, Eugene W., and Claes Fornell. (1993). "A Customer Satisfaction Research Prospectus." In Richard L. Oliver and Roland T. Rust (Eds.), Service Quality: New Directions in Theory and Practice (pp. 239-266). Newbury Park, CA: Sage.

Anderson, Eugene W., Claes Fornell, and Donald R. Lehmann. (1994). "Customer Satisfaction, Market Share, and Profitability." Journal of Marketing 56 (July), 53-66. 
Bass, Frank M. (1993). "The Future of Research in Marketing: Marketing Science." Journal of Marketing Research 30(1) (February), 1-6.

Fornell, Claes. (1992). "A National Customer Satisfaction Barometer: The Swedish Experience." Journal of Marketing (January), 1-21.

Johnson, Michael D., Eugene W. Anderson, and Claes Fornell. (1995). "Rational and Adaptive Expectations in a Customer Satisfaction Framework." Journal of Consumer Research 21 (March), 695-707.

Johnson, Michael D., and Claes Fornell. (1991). "A Framework for Comparing Customer Satisfaction Across Individuals and Product Categories." Journal of Economic Psychology 12(2), 267-286.

Maddala, George S. (1977). Econometrics. New York: McGraw-Hill.

Marshall, Alfred. (1980). Principles of Economics. London: McMillan.

Morrison, Donald G. (1979). "Purchase Intentions and Purchase Behavior." Journal of Marketing 43 (Spring), 65-74.

Oliver, Richard L. (1980). "A Cognitive Model of the Antecedents and Consequences of Satisfaction Decisions." Journal of Marketing Research 17 (November), 460-469.

Olson, Jerry C., and Jacob Jacoby. (1971). "A Construct Validity Study of Brand Loyalty." Proceedings of the 79th American Psychological Association Conference (pp. 657-658).

Pessemier, Edgar A. (1959). "A New Way to Determine Buying Decisions." Journal of Marketing 24 (October), $41-46$.

Wikstrom, Sloveig. (1983). "Another Look at Consumer Dissatisfaction as a Measure of Market Performance." Journal of Consumer Policy 6, 19-35. 